\title{
Heparan sulfate proteoglycan binding promotes APRIL-induced tumor cell proliferation
}

\author{
J Hendriks ${ }^{1}$, L Planelles ${ }^{2}$, J de Jong-Odding ${ }^{1}$, G Hardenberg ${ }^{1}$, \\ ST Pals ${ }^{3}$, M Hahne ${ }^{2}$, M Spaargaren ${ }^{3}$ and JP Medema ${ }^{\star, 1}$ \\ ${ }^{1}$ Department of Clinical Oncology, Leiden University Medical Center, \\ Albinusdreef 2, Leiden 2333 ZA, The Netherlands \\ 2 Institute de Génétique Moléculaire de Montpellier, CNRS UMR5535, 1919 \\ Route de Mende, 34293 Montpellier cedex 5, France \\ ${ }^{3}$ Department of Pathology, Academical Medical Center, Meibergdreef 9, \\ Amsterdam $1105 \mathrm{AZ}$, The Netherlands \\ * Corresponding author: JP Medema, Department of Clinical Oncology, K-1P, \\ LUMC, Albinusdreef 2, Leiden 2333 ZA, The Netherlands. \\ Tel: + 31-71-5261180; Fax: + 31-71-5266760 \\ E-mail: jpmedema@lumc.nl
}

Received 03.2.05; revised 21.3.05; accepted 21.3.05; published online 22.4.05 Edited by G Melino

\begin{abstract}
APRIL, a proliferation-inducing ligand, is a member of the tumor necrosis factor (TNF) family that is expressed by various types of tumors and influences their growth in vitro and in vivo. Two receptors, transmembrane activator and cyclophilin ligand interactor (TACl) and B-cell maturation antigen (BCMA), bind APRIL, but neither is essential for the tumor-promoting effects, suggesting that a third receptor exists. Here, we report that APRIL specifically binds to heparan sulfate proteoglycans (HSPG) on the surface of tumor cells. This binding is mediated by the heparin sulfate side chains and can be inhibited by heparin. Importantly, BCMA and HSPG do not compete, but can bind APRIL simultaneously, suggesting that different regions in APRIL are critical for either interaction. In agreement, mutation of three lysines in a putative heparin sulfate-binding motif, which is not part of the TNF fold, destroys interaction with HSPG, while binding to BCMA is unaffected. Finally, whereas interaction of APRIL with HSPG does not influence APRIL-induced proliferation of $T$ cells, it is crucial for its tumor growth-promoting activities. We therefore conclude that either HSPG serve as a receptor for APRIL or that HSPG binding allows APRIL to interact with a receptor that promotes tumor growth.

Cell Death and Differentiation (2005) 12, 637-648.

doi:10.1038/sj.cdd.4401647

Published online 22 April 2005
\end{abstract}

Keywords: survival; glycobiology; tumorigenesis; APRIL; TNF family

Abbreviations: APRIL, a proliferation-inducing ligand; BCMA, B-cell maturation antigen; FGF-2, fibroblast growth factor 2; HGF, hepatocyte growth factor; HSPG, heparan sulfate proteoglycans; HSGAG, heparan sulfate glycosaminoglycans; TACl, transmembrane activator and cyclophilin ligand interactor; $\mathrm{TI}$, thymus independent

\section{Introduction}

APRIL, a proliferation-inducing ligand, is a member of the tumor necrosis factor (TNF) family of ligands that is processed by a furin convertase inside the Golgi apparatus. ${ }^{1}$ As it is intracellularly cleaved to its mature secreted form, it does not reside on the cell surface like most TNF family members, ${ }^{2}$ but is solely produced as a secreted ligand. APRIL serves an important role in immunological responses. It is expressed by dendritic cells, macrophages, $\mathrm{T}$ and $\mathrm{B}$ cells ${ }^{3-5}$ and in vitro enhances T- and B-cell proliferation and T-cell survival. ${ }^{6}$ In vivo, APRIL affects thymus-independent (TI) B-cell responses, as APRIL-Tg mice mount significantly higher responses to $\mathrm{TI}$ antigens. ${ }^{6}$ In agreement, APRIL secreted by dendritic cells directly signals class switching in an in vitro model. ${ }^{7}$ Moreover, IgA class switching in vivo appears to depend critically on APRIL. ${ }^{8}$ Despite these immunological functions, it was APRIL's pathological function that originally instigated interest in this ligand. The identification of APRIL as a TNF family member that is expressed by a variety of tumor cells of different origin has led to the hypothesis that APRIL is involved in the formation and/or maintenance of tumors. ${ }^{9}$ Indeed, APRIL was shown to contain a remarkable capacity to reinforce tumor growth of both solid and lymphoid tumors in vitro. ${ }^{9}$ This role in maintenance and/or growth was substantiated in vivo by the observation that APRIL-transfected tumor cells grow out more rapidly in nude mice and that inhibition of APRIL has dramatic inhibitory effects on the outgrowth of tumor cells that secrete APRIL. ${ }^{9,10}$ Our recent observations strengthen these observations even further and indicate that APRIL actually promotes tumor formation as APRIL-Tg mice display a high incidence of B-1 B-cell lymphomas at later age. ${ }^{11}$

Currently, two TNF receptor family members, transmembrane activator and cyclophilin ligand interactor (TACl) and B-cell maturation antigen (BCMA), have been shown to bind APRIL with high affinity. ${ }^{12-15}$ Both receptors are shared with BAFF (also BLyS, THANK, TALL-1, zTNF4) (for a review see Mackay et $a A^{A}$ ), another ligand of the TNF family. However, neither receptor appears crucial for the tumor-promoting effects of APRIL. For instance, treatment of Jurkat T leukemia cells with APRIL stimulates their proliferation, but these cells lack both TACl and BCMA expression. ${ }^{10}$ Similarly, the in vivo effects of APRIL on NIH-3T3 fibroblasts, HT29 colon carcinoma cells or A549 lung epithelial cells are not mediated by either receptor, as these tumor cells do not express TACI or BCMA. ${ }^{10}$ Finally, BAFF does not induce tumor cell proliferation nor does it bind to APRIL-responsive tumor cells (Rennert et $a f^{10}$ and unpublished observations). This has led to the assumption that a third receptor for APRIL exists that is thought to mediate the tumor-promoting effects induced by APRIL. Here, we describe that heparan sulfate proteoglycans (HSPG) mediate binding of APRIL to tumor cells as well as primary lymphoid cells and are essential for APRIL-induced tumor proliferation. 


\section{Results}

\section{Detection of APRIL receptors}

In order to identify a third APRIL receptor, we first devised a FACS-based method that allowed for the detection of APRIL receptors on the surface of cells. To this end, Jurkat cells were incubated with recombinant purified MEGA-APRIL under conditions that facilitated receptor binding and that were shown to induce proliferation. ${ }^{9}$ Cell surface-bound APRIL was detected via the FLAG-tag at the N-terminus of this form of APRIL. This assay allowed us to detect binding of APRIL to Jurkat T leukemia cells, A549 lung carcinoma cells and NIH3T3 murine fibroblast-like cells (Figure 1a), which were all previously reported to respond to APRIL treatment. ${ }^{9,10} \mathrm{We}$ also clearly detected binding of APRIL to 293 human embryo kidney cells (293vector, Figure 1 b) as well as a plethora of other cell types tested (Table 1). Therefore, to ascertain that our assay was truly detecting APRIL binding sites, we transfected 293 cells with TACl (293TACl), one of the known receptors for this ligand ${ }^{13-15}$ or with empty vector (293vector). 293TACl cells displayed significantly increased binding of APRIL as compared to 293vector (Figure 1b). Similar observations were obtained when 293 cells were transfected with BCMA (unpublished observations), indicating that our FACS-based assay revealed specific APRIL binding sites. A further validation of this binding was obtained when recombinant APRIL was pretreated with a 10-fold excess of recombinant soluble BCMA-Fc prior to the addition to cells, in order to compete for binding. This treatment prevented the additional binding of APRIL to 293TACl, but surprisingly completely failed to inhibit the basal binding to 293vector cells (Figure 1c). This suggests that binding to 293 and a range of other cells is mediated by a different receptor or is due to a nonspecific interaction. This latter possibility, nevertheless, appeared less likely as several cell types tested (MBL-2, YAC1, WEHI-S21) revealed no or little interaction with APRIL, while the interaction with other cell types clearly varied in intensity (Figure 1a, Table 1).

\section{Heparin prevents APRIL binding}

As mentioned before, APRIL is a secreted TNF family member due to processing by a furin convertase in the Golgi apparatus. ${ }^{1}$ This cleavage at Arginine 104 yields the mature secreted form. Figure $1 \mathrm{C}$ shows that BCMA-Fc could not prevent binding of APRIL to 293 cells, which suggests that the APRIL region that mediates this interaction is outside of the classical TNF fold, or at least different from BCMA binding sites. The recent clarification of the crystal structure of APRIL revealed that the $\mathrm{N}$-terminal amino acids of the secreted ligand are apparently not required for this TNF-like domain. ${ }^{16}$ Closer inspection of the $\mathrm{N}$-terminal part of the ligand shows a

Figure 1 APRIL receptor expression. (a) Jurkat, A549 and NIH-3T3 were stained with recombinant MEGA-APRIL to visualize APRIL receptor expression. $\mathrm{Co}_{\mathrm{in}}$ all figures represents an isotype control staining and is set as the background fluorescence. (b and c) The 293 human embryo kidney cells transfected with vector (293vector) or TACI (293TACl) were analyzed for APRIL receptor levels with recombinant MEGA-APRIL in the absence (b) or presence (c) of a 10-fold excess of BCMA-Fc basic region that could be crucial for binding to 293 cells. Basic ligand regions have been reported to bind cells in a heparinsensitive manner. APRIL was therefore treated with heparin
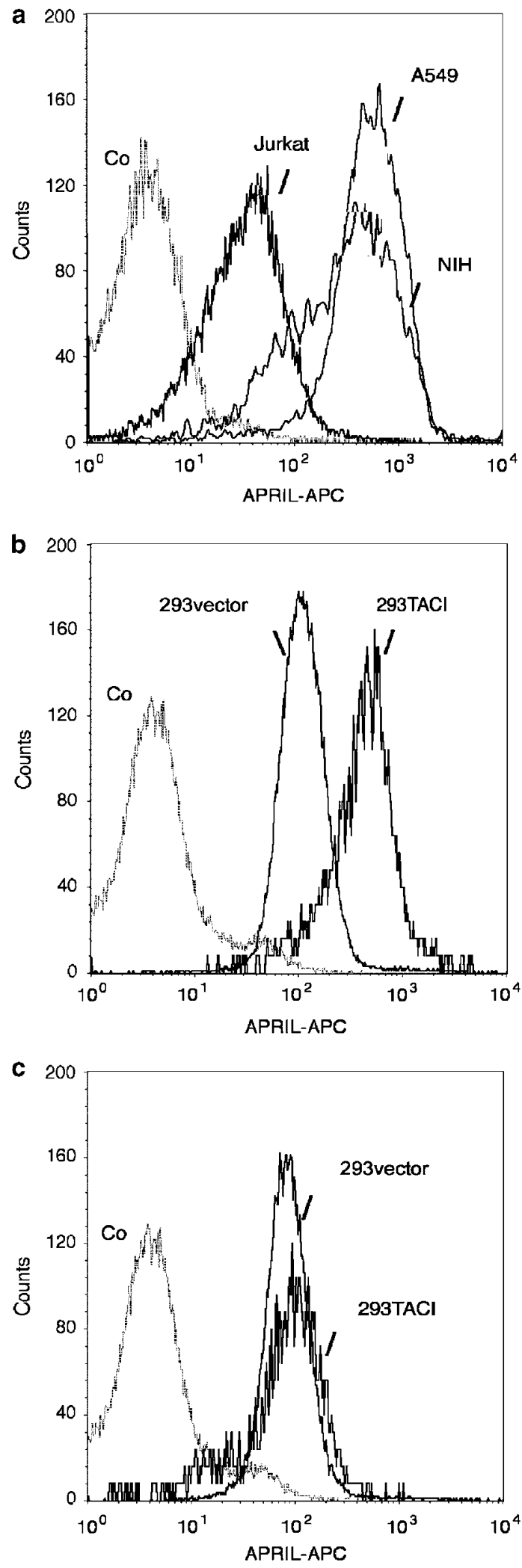
Table 1 APRIL binding to tumor cells

\begin{tabular}{lc}
\hline Cell line & ${\text { Median } \mathbf{M F}^{\mathbf{a}}}^{\text {(fold over background) }}$ \\
\hline SKW6.4 & 3.2 \\
SW620 & 5.4 \\
293T & 22.9 \\
HT-29 & 42.0 \\
BLM & 31.6 \\
Cos-1 & 41.8 \\
TC-1 & 9.0 \\
YAC-1 & 1.3 \\
CMT93 & 12.4 \\
MC-38 & 14.3 \\
MEF & 15.4 \\
XhoC3 & 42.2 \\
AF-11 & 9.3 \\
MBL-2 & 1.0 \\
WEHI-S21 & 1.1 \\
\hline
\end{tabular}

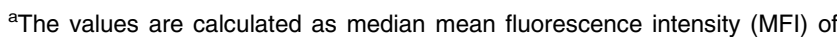
APRIL binding divided by the median MFI of the background. SKW6.4 is a human B-cell lymphomas, SW620 and HT-29 are human colon carcinomas, BLM is a human melanoma, 293T is a SV40 large T-expressing 293 line. Cos-1 are monkey kidney cells, TC-1 is a mouse lung carcinoma, CMT93 and MC-38 are murine colon carcinomas, MEF is a murine embryo fibroblast and $\mathrm{XhoC3}$ and $\mathrm{AF} 11$ are adenovirus or adenovirus and mtRas-transformed counterparts respectively. MBL-2 is a murine T-cell lymphoma and WEHI-S21 is a murine fibroblast-like line

prior to incubation with 293 cells. This pretreatment completely prevented APRIL from binding to 293 cells (Figure 2a). Similarly, dextran sulfate inhibited binding to 293 cells as well (unpublished observations). Despite its dramatic effects on 293 binding, heparin was inadequate in inhibiting the interaction of APRIL with TACI- or BCMA-transfected 293 cells (Figure $2 b$, unpublished observations). The slight reduction in fluorescence intensity observed when TACltransfected cells are treated with heparin (Figure $2 b$ ) is likely due to a decrease in basal, non-TACI-dependent APRIL binding. In agreement, transfection of WEHI-S21 cells, which do not contain endogenous heparin-dependent APRIL binding sites, with TACl induced significant APRIL binding that was unaffected by heparin (Figure 2c). These observations indicate that the interaction with the two classical TNF receptors is not dependent on this heparin-interaction site. MEGA-APRIL, which is used for the receptor visualization, contains a FLAG-tagged trimerization domain (ACRP30) besides the APRIL ligand part. We therefore first analyzed whether this trimerization domain is responsible for the heparin-dependent interaction. This was excluded by the observation that binding of a control FLAG-tagged ACRP30 protein showed no interaction with 293 cells (Figure 2d). Moreover, a His-tagged form of human APRIL (R\&D systems) that lacks this ACRP30 trimerization domain display heparin-sensitive binding as well (Figure 2e), indicating that the heparin-sensitive binding is mediated by APRIL itself.

Importantly, heparin-sensitive binding of APRIL is not restricted to 293 cells. Binding of APRIL to NIH-3T3, Jurkat T leukemia cells and A549 lung carcinoma is in all cases completely inhibited by heparin pretreatment (Figure $2 f$ and unpublished observations). Combined, these observations indicate that secreted APRIL contains a domain, likely outside of the classical TNF fold, that binds tumor cells in a heparinsensitive manner.

\section{HSPGs binding}

Heparin is a rather pleiotropic agent that interferes in several physiological processes. ${ }^{17}$ Previously, we have shown that the heparin-binding growth factor HGF specifically interacts with the HSPG syndecan-1 and the heparin sulfate (HS) containing CD44 and that this interaction promotes c-Met signaling. ${ }^{18,19}$ Syndecans and glypicans together constitute the core amount of HSPGs on the cell surface. ${ }^{17}$ Binding of HGF to HSPG is mediated by the heparan sulfate glycosaminoglycan (HSGAG), side chains and importantly is affected by heparin. ${ }^{19,20}$ To evaluate the role of HSPG in APRIL binding, we made use of an established set of transfectants of the Burkitt's lymphoma line Namalwa. ${ }^{18,19}$ This cell line by itself has relatively little HSPG expression on its cell surface as can be determined with the use of the monoclonal antibody 10E4, which is directed against the HS side chains (Figure 3a). Previously, we reported on the binding of HGF to two CD44 Namalwa transfectants. CD44 is a cell surface molecule that can be differentially spliced and one of its alternatively spliced exons can be coated with HS. In agreement, Namalwa cells expressing CD44 standard (CD44s) did not display increased levels of HSPG on their cell surface (Figure $3 a$ ), nor did they efficiently interact with HGF. ${ }^{19}$ However, the alternatively spliced form CD44v3-10, which contains the HSGAG-modified region encoded by exon 3 showed elevated HSPG levels (Figure 3a) and displayed increased HGF binding. ${ }^{19}$ In addition, a Namalwa syndecan-1 transfectant displayed a much more dramatic elevation of HSPG (Figure 3a). We used these lines to determine the effect of HSPG expression on APRIL binding. Parental Namalwa cells showed APRIL binding, which is only in part sensitive to heparin pretreatment (Figure $3 \mathrm{~b}$ ). This is in line with the reported Iow BCMA expression in this Burkitt's lymphoma line. ${ }^{10}$ APRIL binding to Namalwa CD44s cells was comparable to the parental line, indicating that CD44 itself is not binding APRIL (Figure 3c). However, Namalwa cells expressing the alternatively spliced form of CD44 (CD44v310) contained a clearly larger number of APRIL binding sites, while the syndecan-1 transfectant showed even higher binding (Figure 3c). Similar to the parental Namalwa cells, residual APRIL binding to the Namalwa transfectants remained upon heparin treatment (Figure $3 b$ and d). Nevertheless, all additional, CD44v3-10- and syndecan-1-dependent, APRIL binding sites were sensitive to heparin, as the binding of APRIL to all transfectants is identical in the presence of heparin and is comparable to the heparininsensitive binding to the parental Namalwas (Figure 3d). Similar observations were obtained with 293 cells transfected with CD44s or CD44v3-10 (unpublished observations). These data therefore point to HSPG as the unknown third receptor for APRIL.

\section{APRIL binds to HS side chains of HSPG}

Overexpression experiments do not conclusively determine HSPG as the sole receptor of APRIL on 293 cells as other, 

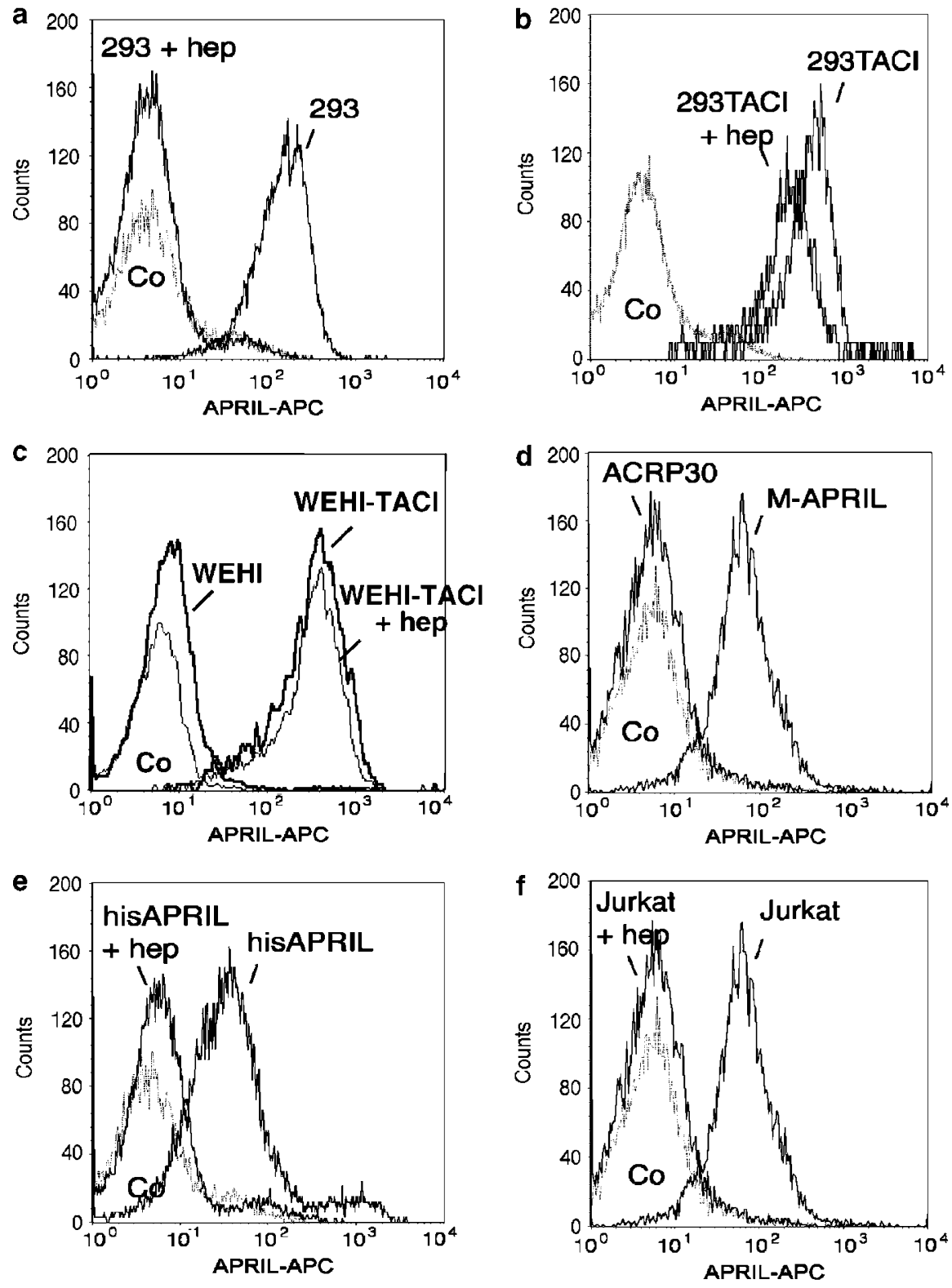

Figure 2 APRIL binding to tumor cells is heparin sensitive. Parental 293- (a) or TACl-transfected 293 cells (293TACI) (b) were stained with MEGA-APRIL in the absence or presence of heparin. (c) Staining of WEHI-S21- or TACI-transfected WEHI-S21 cells with MEGA-APRIL in the absence or presence of heparin (only shown for the TACl transfectant). (d and e) Staining of parental 293 cells with MEGA-APRIL or control FLAG-tagged ACRP30 protein (d) or with His-tagged APRIL in the absence or presence of heparin (e). (f) Jurkat staining with MEGA-APRIL in the absence or presence of heparin. Co in all figures represents an isotype control background measurement

for instance, chondroitin sulfate containing proteoglycans could interact with APRIL as well. Heparitinase, isolated from Flavobacterium heparinum, specifically cleaves the HS side chains of HSPG. Cleavage can be monitored by the disappearance of cell surface staining with the $m A b$ 10E4 and the appearance of staining with the mAb 3G10, which interacts with HS stubs that are left behind after heparitinase treatment. ${ }^{21}$ Complete HS side chain cleavage of the Namalwa transfectants was attained during a $2 \mathrm{~h}$ heparitinase incubation. ${ }^{19}$ Importantly, these treated CD44s or CD44v3-10 expressing Namalwa cells no longer bound APRIL in a heparin-sensitive manner and display APRIL binding that is comparable to the heparin-pretreated cells (Figure $4 \mathrm{a}$ ). This suggests that HSGAG present on the HSPG mediate APRIL binding. This conclusion was further supported by heparitinase treatment of 293 cells, which resulted in processing of practically all HSPG to yield the typical stubs as monitored by the disappearance of 10E4 staining and the appearance of $3 G 10$ reactivity (Figure 4b). As a consequence of this strong reduction in HS side chains, APRIL failed to bind to 293 cells (Figure 4b). In conclusion, our data indicate that $\mathrm{HS}$ side chains of HSPG mediate the interaction of APRIL with a wide variety of tumor cells. 

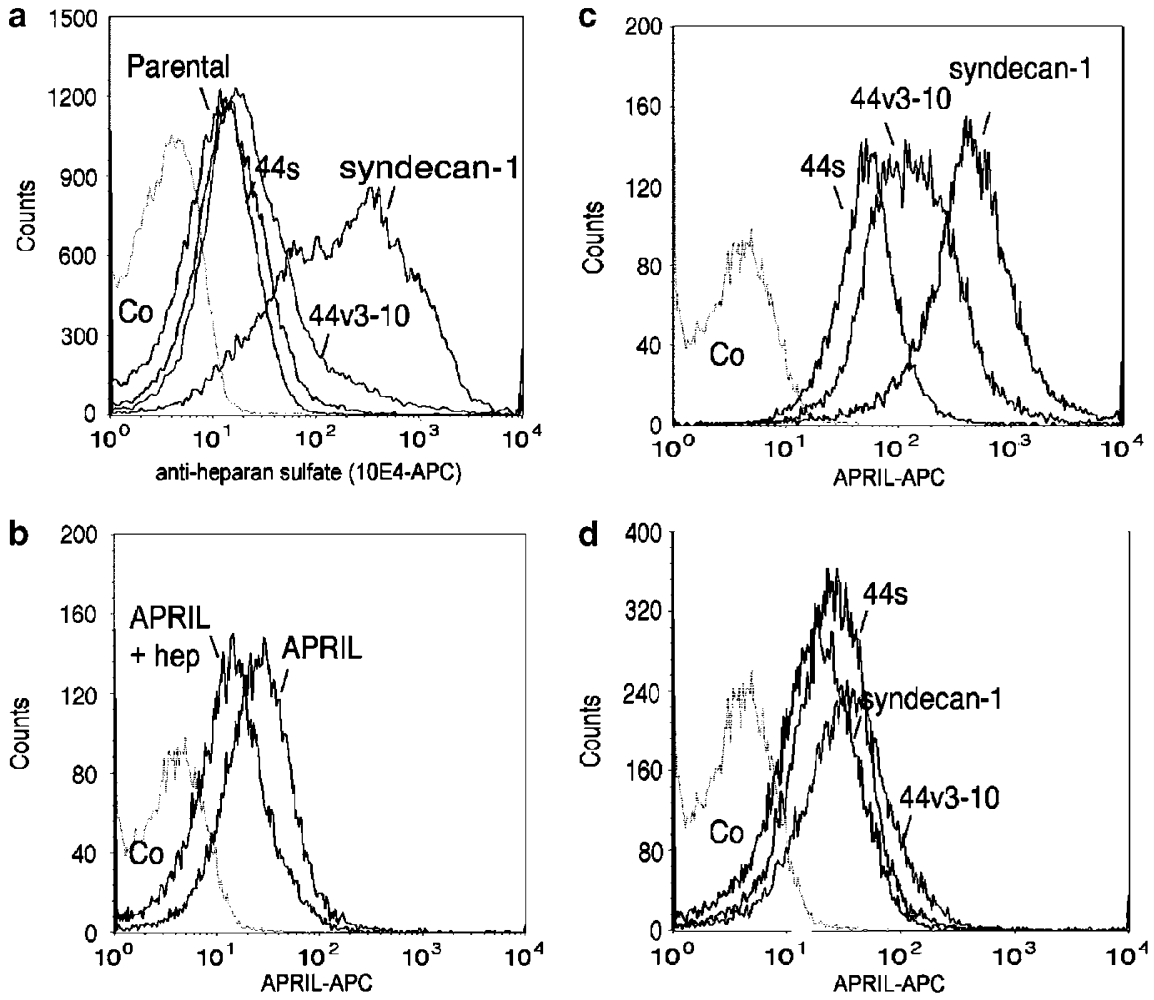

Figure 3 HSPG overexpression increases APRIL binding. (a) expression levels of HSPG on parental Namalwa Burkitt's lymphoma cells, or CD44s, CD44v3-10 and syndecan-1 transfectants of this line. (b) APRIL binding to Namalwa parental cells in the absence or presence of heparin. (c and d) APRIL staining of Namalwa transfectants CD44s, CD44v3-10 and syndecan-1 in the absence (c) or presence (d) of heparin. Co in all figures represents an isotype control background measurement

\section{Identification of the HS-binding motif in the $\mathrm{N}$-terminus of SAPRIL}

Consensus sequences for heparin and HSPG binding have been described. ${ }^{22}$ We used these sequences to analyze which amino acids in the N-terminus of APRIL could be of importance in binding to HSPG. One such consensus sequence is $X B X B B X$, in which $B$ is a basic residue $(K, R$ or $\mathrm{H})$ and $X$ is preferably hydrophobic. A corresponding sequence in the N-terminal part of the secreted form of APRIL (SAPRIL) that has the right order of basic residues is $\mathrm{Q}^{109} \mathrm{~K}^{110} \mathrm{Q}^{111} \mathrm{~K}^{112} \mathrm{~K}^{113} \mathrm{Q}^{114}$. To analyze whether this region was crucial in HSPG binding, we mutated the three lysines to alanine (Figure 4c). This alanine substituted form of SAPRIL (SAPRIL ${ }^{3(\mathrm{~K}-\mathrm{A})}$ ) was produced in the supernatant of transfected 293 cells to a similar level $(\sim 1 \mathrm{ng} / \mu \mathrm{l})$ as the normal form (Figure $4 d$ ). Usage of this SAPRIL-containing conditioned medium revealed that both SAPRIL forms bound with comparable efficiency to BCMA-transfected 293 cells (Figure $4 \mathrm{e}$ ), indicating that the alanine substitutions do not interfere with folding of the TNF-like domain or BCMA binding. The wild-type sAPRIL also bound specifically to 293 cells (Figure 4e). However, binding is less efficient as compared to the MEGA-APRIL ligand, even though the amount of SAPRIL present in the conditioned medium is comparable to the MEGA-APRIL concentration used for staining. It is likely that sterical hindrance of the N-terminal HSPG binding site in APRIL with the adjacent anti-FLAG antibody binding site may be of importance for this reduced detection. These two sites are separated by the ACRP30 domain in the MEGA-APRIL protein and are not likely to interfere, but are closely linked in the SAPRIL protein. Despite this lower binding capacity, SAPRIL clearly interacted with 293 cells and this interaction proved heparin sensitive (unpublished observations). In contrast, we observed that the alanine substitutions completely annihilated binding to 293 cells (Figure 4e). This suggests that the HSPG binding site is distinct from the region that mediates BCMA binding and that both interactions could possibly take place simultaneously. To proof this directly, we first incubated SAPRIL or SAPRIL ${ }^{3(\mathrm{~K}-\mathrm{A})}$ with heparin-sepharose beads. While the wild-type form nicely interacted with the beads, the mutant form was not precipitated (Figure 4f). Subsequent incubation of these beads with recombinant BCMA-Fc revealed that the soluble receptor can interact with APRIL bound to the beads, while it failed to bind to empty beads or SAPRIL ${ }^{3(\mathrm{~K}-\mathrm{A})}$ incubated beads (Figure 4f). An important consequence of this precipitation is the fact that both ligand regions can apparently be occupied at the same time. We therefore conclude that APRIL binds HSPG via the lysine-rich region in the $\mathrm{N}$-terminal part of the secreted ligand and that this leaves the TNF-like region free to interact with other receptors. 


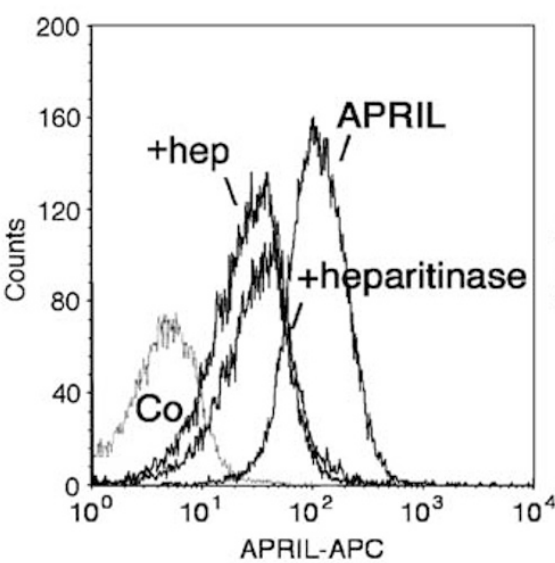

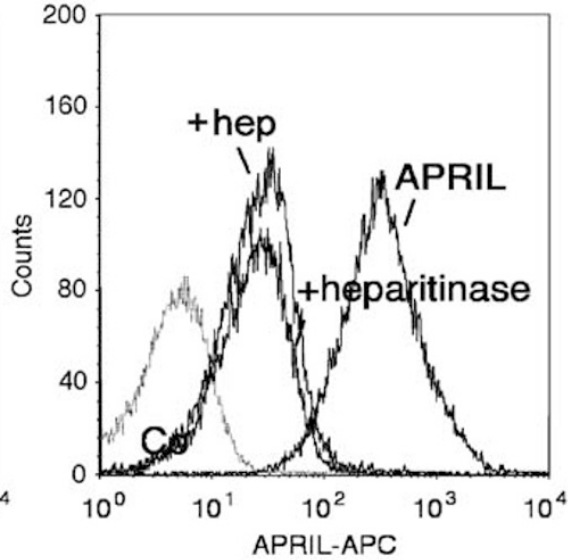

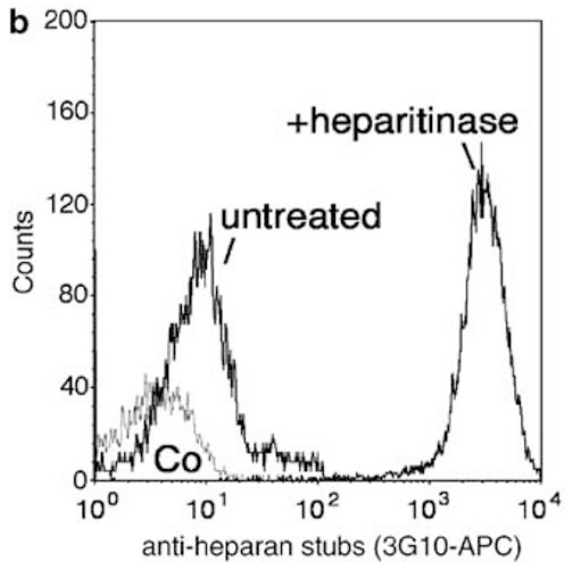

C

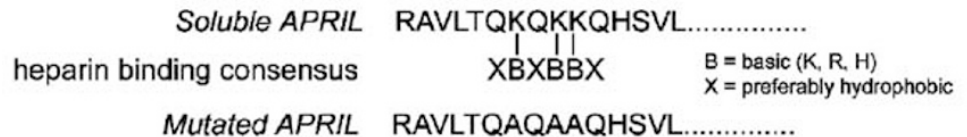

Mutated APRIL RAVLTQAQAAQHSVL
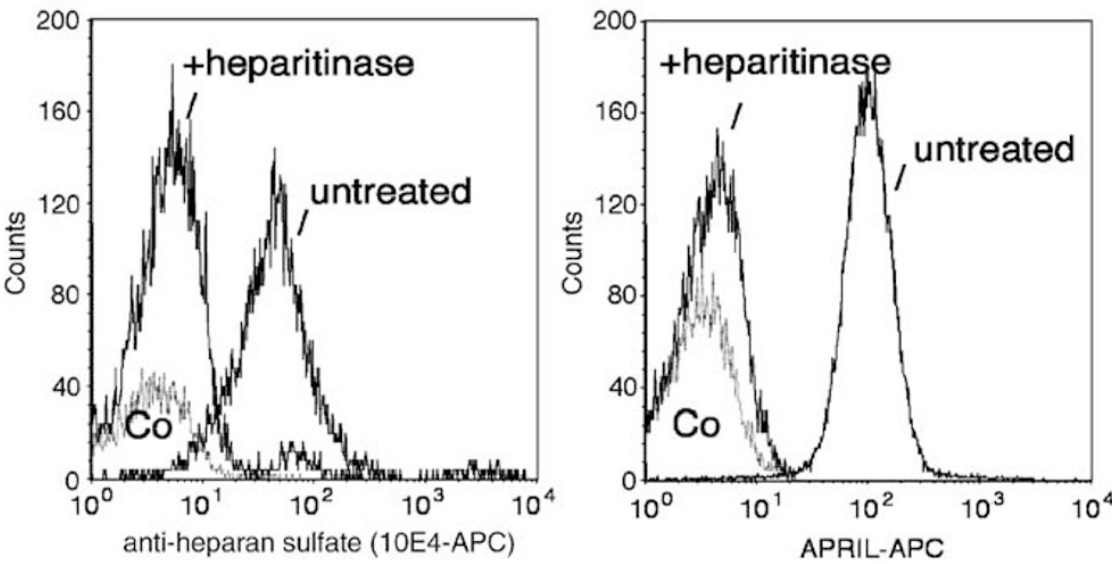

d
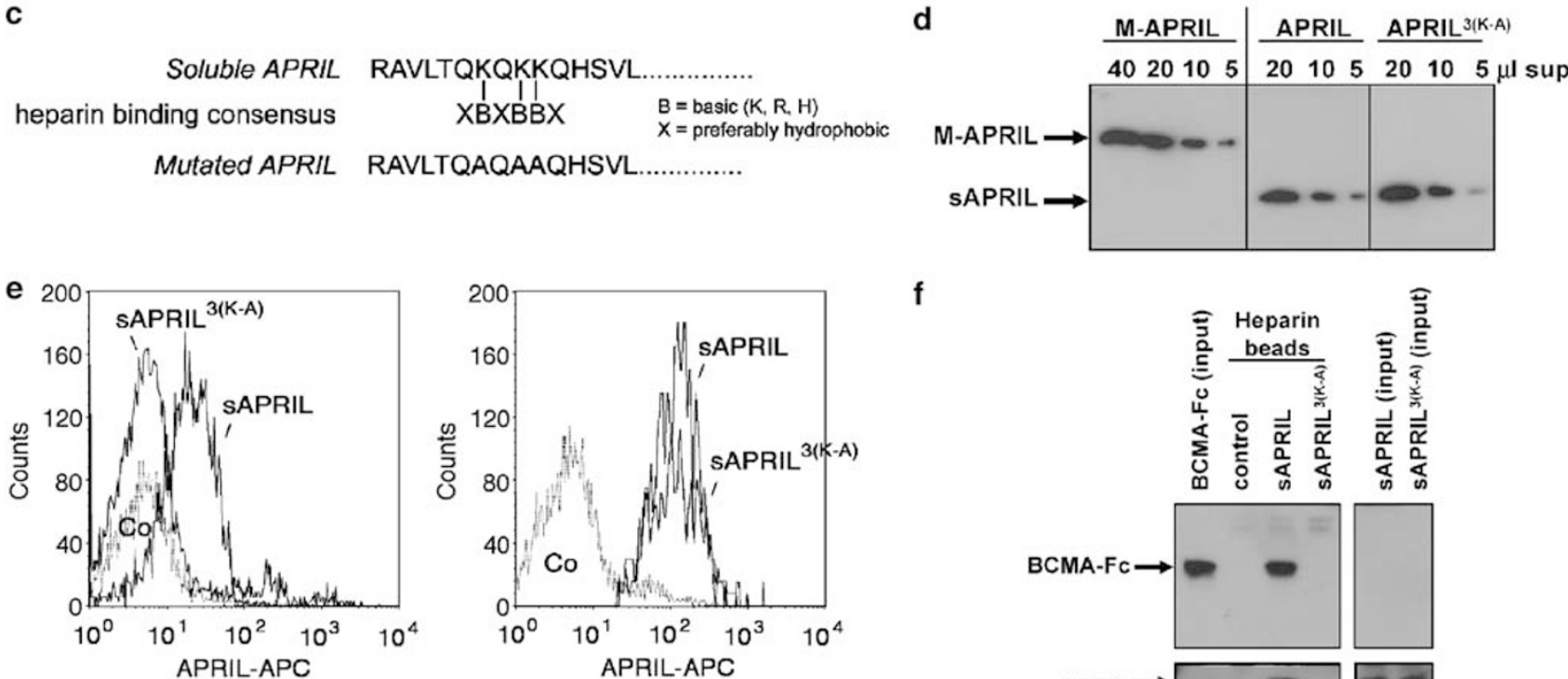

f

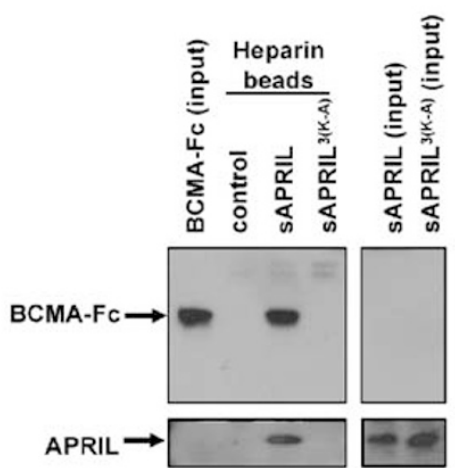

Figure 4 Heparitinase treatment of tumor cells prevents APRIL binding. (a) Namalwa CD44s (left panel) and CD44v3-10 (right panel) cells were treated with heparitinase and then stained for APRIL receptor expression with MEGA-APRIL in the absence or presence of heparin. Similar observations were obtained for Namalwa parental and syndecan-1 cells. (b) Expression of heparan stubs (left panel), HS moieties (middle panel) and MEGA-APRIL binding to 293 cells (right panel), before and after heparitinase treatment. (c) The N-terminal part of secreted APRIL, which starts with the arginine, contains a sequence that is comparable to a heparin-binding consensus site. In a mutated SAPRIL, the essential lysines in this consensus sequence are mutated to alanine. (d) Production of sAPRIL and the mutated form SAPRIL ${ }^{3(K-A)}$ by transient transfected 293 cells. Serial dilutions of conditioned medium of SAPRIL or SAPRIL ${ }^{3(K-A)}$-transfected 293 cells were loaded on SDS-PAGE and Western blotted using anti-FLAG-HRP. As a control set amounts of MEGA-APRIL (in ng) were loaded on the gel. (e) Binding of sAPRIL and sAPRIL ${ }^{3(\mathrm{~K}-\mathrm{A})}$ to untransfected 293 cells (left plot) or BCMA-transfected 293 cells (right plot). (f) Heparin-sepharose beads were incubated with PBS, SAPRIL or SAPRIL ${ }^{3(K-A)}$ and washed three times prior to incubation with recombinant BCMA-Fc. Precipitates were washed again and loaded on SDS-PAGE. As controls, input BCMA-Fc, SAPRIL and SAPRIL $^{3(\mathrm{~K}-\mathrm{A})}$ were loaded directly on the gel. Upper panel was developed with anti-human Ig $(\mathrm{Fc})$ and the lower panel with anti-FLAG to reveal FLAG-tagged sAPRIL 


\section{APRIL-induced proliferation and immune cell binding}

Recently, we have shown that peritoneal B-1 B cells bind APRIL, which instills a survival advantage to these cells. ${ }^{11}$ Prolonged exposure of $B-1 B$ cells to APRIL eventually leads to B-1 lymphoma formation. ${ }^{11}$ Binding of APRIL to B-1 B cells was also largely prevented by heparin (Figure $5 \mathrm{a}$ ), although some residual binding was retained. This is in line with the fact that B-1 B cells express $\mathrm{TACl}^{23}$ Similar to B-1 B cells, peritoneal B-2 B cells and T cells displayed heparin-sensitive APRIL binding, and also in this case nonheparin-sensitive binding is observed (Figure 5a). Previously, T cells were shown to be costimulated by APRIL. ${ }^{13,24}$ To analyze whether this involves heparin-sensitive binding sites, $T$ cells were stimulated with suboptimal amounts of anti-CD3 in the absence or presence of APRIL and the effect of heparin on this stimulation was analyzed. As was reported before, ${ }^{25}$ heparin itself elevates CD3-induced T-cell activation (Figure 5b, left plots). More importantly, APRIL also provided clear costimulation of $\mathrm{CD}^{+}{ }^{+} \mathrm{T}$ cells (Figure $5 \mathrm{~b}$ ). Costimulation is clearest at early time points (Figure $5 \mathrm{~b}, 24 \mathrm{~h}$ ) when the activation of the T cells is still limited, and is also observed after $48 \mathrm{~h}$ when the activation of the T cells is more pronounced (unpublished observations). Nevertheless, there is a highly reproducible 1.5 to 2 -fold increase (12.8-19.5\%) in activated $\left(\mathrm{CD} 69^{+} / \mathrm{CD} 25^{+}\right) \mathrm{CD} 4^{+} \mathrm{T}$ cells when MEGA-APRIL is added to the cultures. Even though heparin by itself elevated CD3-induced CD4 ${ }^{+}$T-cell activation, MEGA-APRIL was still capable of potentiating this T-cell activation by about 1.5 to 2 -fold (21.6-36.6\%), indicating that heparin could not inhibit APRIL-induced costimulation (Figure $5 \mathrm{~b}$ ). This suggests that heparin-sensitive binding is not required for $\mathrm{CD}^{+}{ }^{+} \mathrm{T}$-cell costimulation, and that the binding of APRIL with the TNF region to the classical receptor $\mathrm{TACl}$ may be crucial for this effect.

Originally, APRIL was identified as a TNF family member that induces tumor cell proliferation. Although it is clear that in some cases, for instance, in B-cell neoplasia, APRIL mediates survival rather than proliferation, its capacity to enhance Jurkat and NIH-3T3 tumor cell outgrowth in vitro by $20-40 \%$ has been clearly documented. ${ }^{9}$ A549 and NIH-3T3 cells were also shown to be receptive to APRIL stimulation in vivo. ${ }^{9,10}$ In contrast to the $\mathrm{T}$ cells described above, all APRIL binding to these tumor cells appears to be dependent on HSPG. We therefore directly analyzed whether heparin, which prevents APRIL binding to tumor cells (Figure 2), could also affect APRIL-induced proliferation. Using recombinant MEGAAPRIL, we found that APRIL could enhance the cellular outgrowth of NIH-3T3 cells and Jurkat cells by around 20$30 \%$ (Figure $5 \mathrm{c}$ ), which is in agreement with our previous observations. ${ }^{9}$ Similarly, ${ }^{3} \mathrm{H}$-thymidine incorporation of $\mathrm{A} 549$ was enhanced with about $40 \%$ upon APRIL treatment (Figure 5c). However, when cells were treated at the same time with heparin, the APRIL stimulatory effect on these tumor lines was lost completely (Figure 5c). Taken together, our data indicate that APRIL binds HSPG via its $\mathrm{N}$-terminal portion and that this interaction is blocked by heparin. Binding to HSPG apparently plays no role in T-cell costimulation by APRIL, but is crucial for the effects elicited by APRIL on tumor cells that do not express TACI or BCMA.

\section{Discussion}

APRIL is a proliferation-inducing ligand that is expressed by tumor cells and immune cells and mediates cell proliferation as well as survival, depending on the cellular context. Here, we show that SAPRIL binds with its N-terminal basic region to HSPG. The HSPGs can be either extracellular (e.g. Perlecan, Agrin) or transmembrane proteins (i.e. syndecan-1-4, glypican 1-6 or CD44v3). Via their HS chain, HSPGs can bind growth factors (e.g. Wnt, TGF $\beta$, FGF1/2, IGF, VEGF and HGF), cytokines, chemokines, proteases and protease inhibitors (antithrombin). ${ }^{26-29}$ HSPGs play an important role in a wide variety of biological responses and processes such as adhesion, migration, proliferation, embryonal development, differentiation, morphogenesis, angiogenesis and blood coagulation. ${ }^{26-29}$ HSPGs have also been implicated in cancer, as the HS polymerases EXT1 and 2 have been identified as tumor suppressor genes in hereditary multiple exostoses, whereas syndecan-1 is required for Wnt-1induced mammary tumorigenesis in mice. ${ }^{30,31}$

Several different modes of action have been put forward to explain the highly divergent effects of HSPG on physiological processes. ${ }^{17}$ For instance, for HGF, we have shown that the HSPG CD44v3-10 binds this ligand and thereby increase the activation of the receptor c-Met. ${ }^{18,19}$ The effect is likely due to an increase in the local concentration of HGF, suggesting that HSPG act as captors in the case of HGF. Noteworthy, we have observed a similar role for CD44v3 in HGF/Met signaling in colorectal cancer cells. ${ }^{32,33}$ Moreover, we have demonstrated that syndecan-1 (CD138), which is highly expressed in multiple myeloma, binds HGF and promotes Met signaling in an HS-dependent manner in myeloma cells. ${ }^{34}$ This indicates that HGF binding to HSPG plays a role in tumorigenesis as well.

In the case of FGF-2 binding to HSPG, the increase in local concentration that allows more efficient interaction with FGF-R appears to play a role, but another level of complexity is added. FGF-2, FGF-R and HPSG seem to form a ternary complex that is crucial for signaling. In the absence of HSPG, FGF-2 cell signaling has a transient nature and is not complete, as IkB degradation or proliferation is not observed. ${ }^{35}$ Simultaneous binding to syndecans or glypicans modifies the FGF-2/FGF-R interaction and optimizes FGF-2-induced signaling, which results in sustained ERK2 activation, NFkB activation and proliferation. ${ }^{35}$ In this case, HSPG apparently are essential for the correct receptor/ligand interaction and thus act as cofactors. It is important to note that a similar role for HSPG in HGF cannot be excluded.

Another mode of action of HSPG has been shown to be important for the formation of morphogen gradients during animal development. ${ }^{36}$ In Drosophila, Wingless has been shown to bind to the glypicans Dally and Dally-like protein (DLP) on the surface of cells and this creates a gradient that is essential for wing formation ${ }^{28,37}$ More recently, this model was extended and now includes cleavage of DLP, which results in shedding and conversion of DLP from a cofactor to an antagonist. ${ }^{38,39}$

It remains to be analyzed which mechanism is applicable for APRIL binding to HSPG. It appears unlikely that the effects 
observed in our in vitro tumor cell proliferation assays are due to a gradient. Obviously, this does not exclude a role for gradient formation in vivo. Similarly, we have not observed an effect of increasing the APRIL concentrations by 10- or 100- fold in our in vitro assays, suggesting that an increase in the local concentration due to HSPG-dependent capturing is not likely the mode of action of HSPG in APRIL signaling. We therefore believe that correct positioning and/or ligand
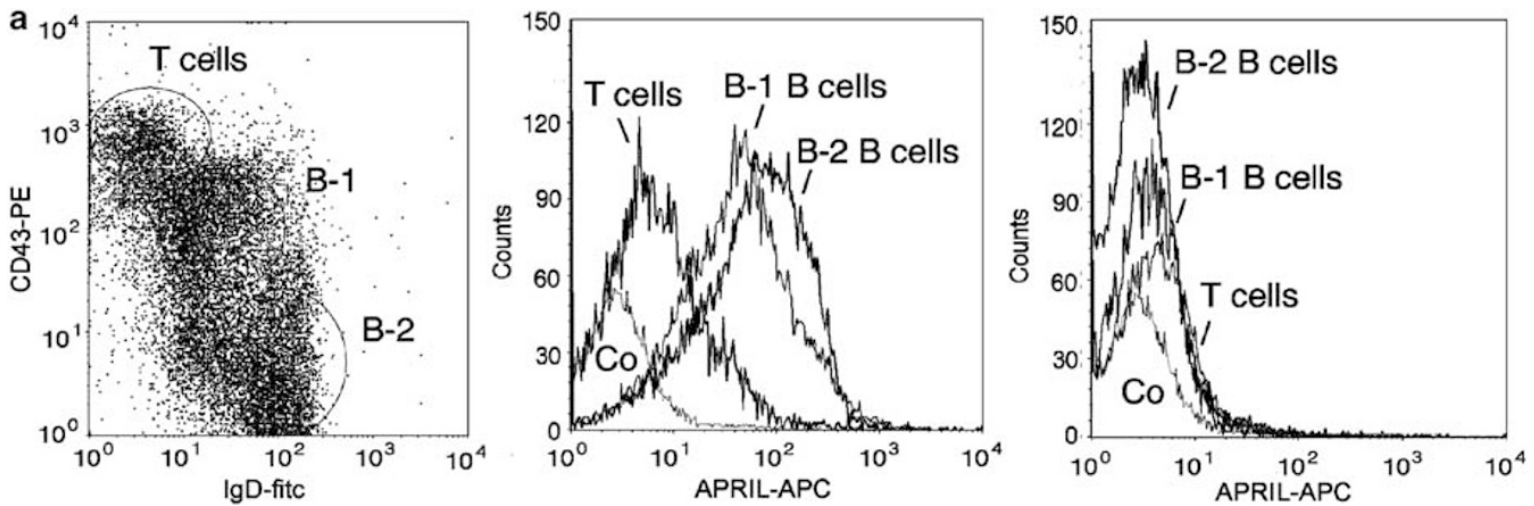

b
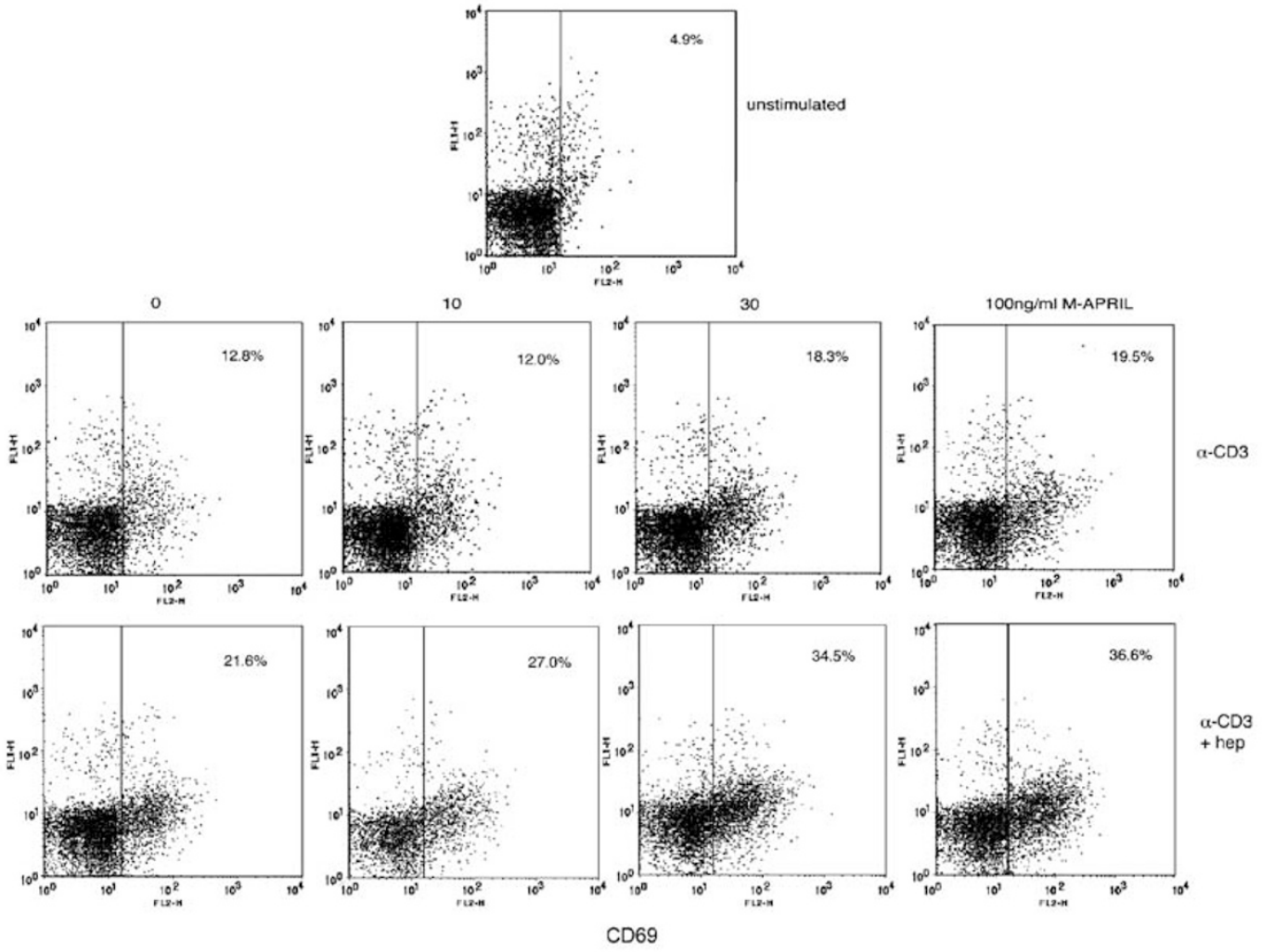

C
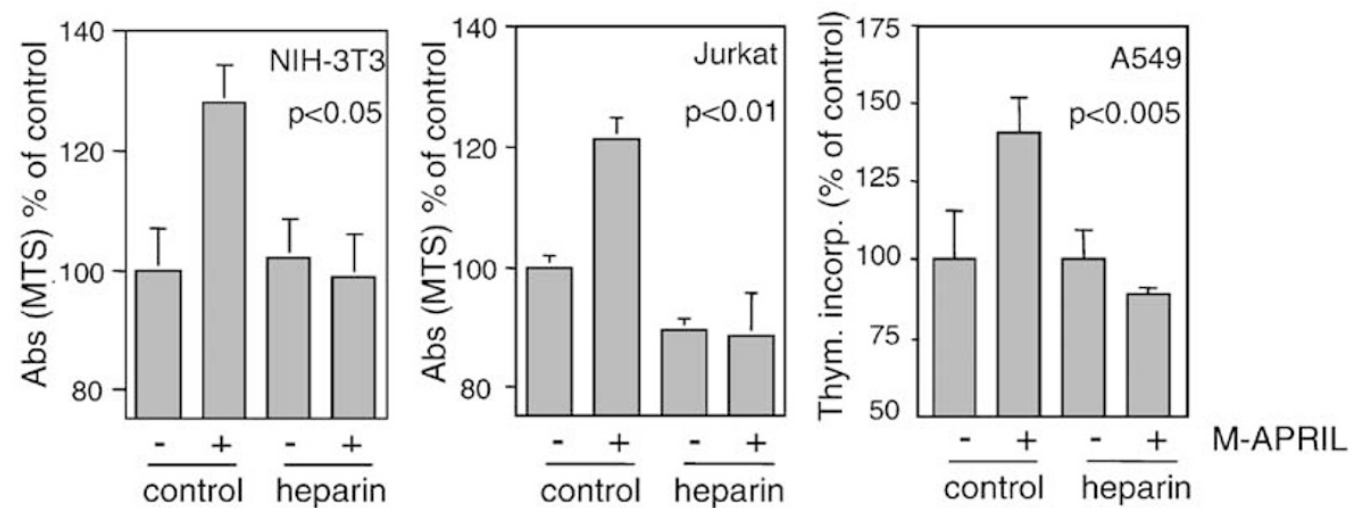
modification by HSPG is a more likely explanation of the effects observed. This would imply that a third receptor, aside from $\mathrm{TACl}$ and $\mathrm{BCMA}$, exists as the tumor lines tested are all reported to be $\mathrm{TACl}$ and $\mathrm{BCMA}$ deficient. ${ }^{10}$ The fact that APRIL is free to interact with BCMA when bound to heparin (Figure 4f) suggests that correct positioning by HSPG is a feasible model for APRIL. Identification of such an HSPGdependent receptor will be a difficult endeavor though, as absolutely no binding of APRIL is detectable in the presence of heparin or in the absence of HSGAG (heparitinase-treated cells). This either points to a very low affinity of APRIL for this receptor, a modification of APRIL by HSPG that allows a novel interaction, or a very low expression level of the receptor. In theory, it could therefore still be possible that BCMA or TACI are expressed in our tumor lines at levels that go unnoticed by the antibodies used and that HSPG act by positioning APRIL for BCMA or TACI.

Even though these are currently the best-described effects of $H S P G$ on ligand effectivity, one additional feature of $H S P G$ should not be ignored. When bound to FGF-2, syndecan-4 not only positions this ligand for FGF-R but also elicits signals itself, like for instance activation of $P K C \alpha,{ }^{40}$ and this can occur in the absence of FGF-R. In this light, it is important to note that syndecan-1-4 contain high sequence similarity in their cytoplasmic tail and that this part is essential for $\mathrm{PKC} \alpha$ activation as well as binding of PIP2, CASK and several other signaling molecules, ${ }^{40,41}$ suggesting that all syndecans could function in a similar manner. In addition, CD44 molecules have been shown to interact, among others, with p56lck and p59fyn. ${ }^{42}$ Binding of APRIL to HSPG could thus directly signal toward proliferation. The specificity of such an effect is difficult to assess though. Other TNF family members contain a similar heparin-binding region in their N-terminus, but are not implicated in tumor cell proliferation. However, different HSPG display clearly different functions and their interactions are far from nonspecific. As such, APRIL-induced tumor cell proliferation could be mediated by a specific HSPG. Alternatively, a specific HSGAG sequence could be of importance to allow for signaling to occur. Previously, tumor cells have been reported to actively influence their affinity for FGF-2 by a change in the overall level of HSPG and the sulfation pattern of these HSPG. ${ }^{17}$ Whether this is also true for APRIL remains to be determined, but could be an underlying reason for the tumor specificity of this ligand. Even though it is clear that the interaction with HSPG is of importance for proliferation, a better insight into this interaction and the signals that are derived from it are needed to provide a better understanding of the role of HSPG in APRIL-induced tumor proliferation.

Heparin-sensitive binding of APRIL likely also plays a role in immunological settings. A large part of the interaction with peritoneal $B-1, B-2$ and $T$ cells is mediated via HSPG, suggesting that they may influence the function of APRIL in immune responses. Whether this is at the level of capturing, positioning or signaling remains to be determined, but at this point, we have not been able to detect an effect of heparin on T-cell costimulation. Previously, T-cell costimulation was shown to occur with BAFF. ${ }^{43}$ This was suggested to occur through $\mathrm{TACl}$, which is expressed upon mouse $\mathrm{T}$-cell activation. ${ }^{44}$ T-cell costimulation of APRIL through $\mathrm{TACl}$ would explain the heparin insensitivity, as this is not expected to be decreased by heparin. However, these TACI expression data were contradicted in a separate study that showed no $\mathrm{TACl}$ or BCMA expression on human $\mathrm{T}$ cells, but instead suggested BAFF costimulation via BAFF-R. ${ }^{45}$ Obviously, this does not exclude a role for the heparin-binding domain in T-cell activation or function in vivo. As we have shown that transgenic APRIL expression affects TI-type antibody responses, which are in part mediated by B-1 B cells, and influences T-cell downsizing, ${ }^{6}$ generation of $\mathrm{APRIL}^{3(\mathrm{~K}-\mathrm{A})}$ transgenic mice will allow an assessment of the function of HSPG in immune responses. A similar approach will need to be taken in order to evaluate the role of the HSPG-binding domain in lymphoma formation. Recently, we have shown that transgenic APRIL expression induces B-1 B-cell lymphomas at later age. ${ }^{11}$ In vivo analysis of lymphoma formation in APRIL ${ }^{3(K-A)}$ mice will be essential. Alternatively, treatment of our APRIL transgenic mice with heparin could potentially affect tumor formation. Clinical data have suggested that administration of antithrombotic agents such as low molecular weight heparins, not only affects coagulation but also appears to have antitumor properties as well. ${ }^{46}$ Conversely, sequestering APRIL has been reported to prevent tumor outgrowth in mice. ${ }^{10}$ Combined these observations could indicate that at least a part of the clinical effect of heparin on solid tumors is mediated by inhibition of APRIL. Future experiments will likely give a better insight into this mechanism, but it is clear that heparin inhibits binding of APRIL to HSPG and prevents the induction of tumor cell proliferation by APRIL.

\section{Materials and Methods}

\section{Cell lines}

The 293 human embryo kidney cells, Jurkat T leukemia cells, A549 lung carcinoma cells and $\mathrm{NIH}-3 \mathrm{~T} 3$ fibroblasts lines were cultured routinely in IMDM plus $8 \%$ FCS, pen/strep, $2 \mathrm{mM}$ glutamine and $50 \mu \mathrm{M} \beta$-ME. The Burkitt's lymphoma line Namalwa and its transfectants were routinely cultured in RPMI 1640 containing 10\% FCS and 10\% Hyclone serum, glutamine, pen/strep and $50 \mu \mathrm{M} \beta$-ME. The transfectants were kept under G418 selection in order to guarantee expression of the transfected

Figure 5 Immune and tumor cell activation by APRIL. (a) MEGA-APRIL staining of peritoneal cells, which are subdivided by CD43-PE and IgD-FITC staining. T cells are $C D 43^{\text {high }}$ and $\lg D^{-}, B-1 B$ cells are $C D 43^{+}$and $\operatorname{lgD}{ }^{\text {low }}$ and $B-2 B$ cells are $C D 43^{-}$and $\lg D^{\text {high }}$. Left plot represents the $C D 43 / \operatorname{lgD}$ staining of peritoneal lymphocytes, middle plot is MEGA-APRIL staining and the right plot is MEGA-APRIL plus heparin staining (b) CD4 ${ }^{+}$T-cell activation was induced with immobilized anti-CD3 with and without APRIL and/or heparin. CD4 ${ }^{+}$T-cell activation is determined after $24 \mathrm{~h}$ with CD4-APC, CD25-FITC and CD69-PE staining and the percentage of active CD4 ${ }^{+} \mathrm{T}$ cells is given in the figure. Experiment shown is representative of three independent activations. (c) Proliferation of NIH-3T3, Jurkat T-cell leukemia and A549 cells is induced by APRIL at $20 \mathrm{ng} / \mathrm{ml}$ (left two panels) or at $200 \mathrm{ng} / \mathrm{ml}$ (right panel). Proliferation of NIH-3T3 and Jurkat is measured after $36 \mathrm{~h}$ with MTS. Values given are a mean of at least four different stimulations and are presented as the percentage of the nontreated cells, which is set to $100 \%$. A549 proliferation was measured after $32 \mathrm{~h}$ with ${ }^{3} \mathrm{H}$-thymidine incorporation. Values given are percentage over control (set to $100 \%$ ) and a mean of a triplicate stimulation 
plasmids. All other cells mentioned in the table were cultured either in the IMDM- or the RPMI-based medium.

\section{APRIL receptor visualization}

Cells were harvested without trypsin to ascertain that receptor expression was not lost and subsequently washed and resuspended in PBS plus $0.5 \%$ bovine serum albumin (PBS/BSA). Per staining, approximately $0.5 \times 10^{6}$ cells were incubated with $50 \mathrm{ng} / 50 \mu \mathrm{l}$ MEGA-APRIL (ALEXIS Benelux, Breda, The Netherlands) or human His-tagged APRIL (R\&D systems Europe, Oxon, UK) or with conditioned medium from APRILproducing cells. After $30 \mathrm{~min}$ at $37^{\circ} \mathrm{C}$ in a regular $\mathrm{CO}_{2}$ incubator, cells were washed free of unbound APRIL with PBS/BSA and incubated for $30 \mathrm{~min}$ on ice with $2 \mu \mathrm{g} / \mathrm{ml}$ anti-FLAG-biotine (Sigma-Aldrich Chemie BV, Zwijndrecht, The Netherlands) or anti-His antibody (Amersham-Pharmacia, Roosendaal, The Netherlands). Bound anti-FLAG-bio was subsequently detected with streptavidin-APC (BD biosciences, Alphen a/d Rijn, The Netherlands) and bound anti-His with goat-anti-Mouse-APC (BD biosciences) with the use of a FACScalibur (BD biosciences). Controls for nonspecific binding consisted of control-conditioned medium in the case of APRIL-containing medium, PBS/BSA incubation or FLAG-taggedACRP30 binding in the case of purified recombinant APRIL.

When indicated, added APRIL was shortly preincubated with $4 \mathrm{IU} / \mathrm{ml}$ unfractionated heparin (hospital pharmacy, LUMC Leiden, The Netherlands) or a 10 -fold excess of BCMA-Fc prior to the incubation at $37^{\circ} \mathrm{C}$.

\section{Transient transfection}

The 293 cells were seeded at $2.5 \times 10^{5} / 6$ well and the next morning transfected using the Fugene transfection method (Roche Diagnostics BV, Almere, The Netherlands) according to the manufacturer's instructions. For the receptor expression, studies pcDNA3.1/empty or TACI plasmids were cotransfected at a 10:1 ratio with pcDNA3.1/eGFP. After $48 \mathrm{~h}$, cells were harvested without trypsin and stained according to the protocol described above. Transfected cells were selected on the FACS with the use of high eGFP expression and compared to nontransfected cells. For APRIL production, cells were transfected with pCR3.1-HA-signal FLAGtag SAPRIL, which encodes the secreted form of APRIL (aa 105-250) with a FLAG-tag separated by a short linker region at the $\mathrm{N}$-terminus and is directed to the medium due to the HA-signal sequence. After transfection, cells were left after for $32-48 \mathrm{~h}$. At this time, the medium was replaced with low amounts of serum-free DMEM in order to obtain optimal APRIL production, and left to produce for another 8-16 h.

\section{Heparitinase treatment}

Namalwa cells and 293 cells were resuspended in PBS at a density of 2$5 \times 10^{6} / 200 \mu$ in normal Eppendorf reaction tubes. $10 \mathrm{mU} / \mathrm{ml}$ heparitinase (MP Biomedicals, Irvine, USA) was added and cells were subsequently incubated while shaking for $2-3 \mathrm{~h}$ at $37^{\circ} \mathrm{C}$. Control incubations were treated identical, but without the addition of enzyme. After the enzymatic step, cells were washed with PBS and PBS/BSA and subjected to staining with 10E4 (anti-HS, Seikagaku, Tokyo Japan) and 3G10 (anti-heparan stub, Seikagaku) to analyze the effectiveness of the treatment and with APRIL as described above to analyze APRIL receptor expression.

\section{APRIL mutation}

pCR3.1 HA-signal FLAG-tag SAPRIL served as a template for a mutation PCR using AAACTGCAGAGAGCAGTGCTCACCCAAGCACAGGCGGC
GCAGCACTCTGTCCTGCAC as forward primer and GCTCTAGATCA CAGTTTCACAAA as reverse. PCR products, which contained three lysine to alanine mutations in the $\mathrm{N}$-terminal part, were cloned into the pCR2.1 TA cloning vector (Invitrogen, Breda, The Netherlands) and sequenced. Correct clones were introduced into the pCR3.1 HA-signal FLAG-tag SAPRIL vector by swapping the original secreted APRIL region with the mutated one using the Pstl and Xbal sites. Expression of this mutated APRIL plasmid yields a secreted lysine-substituted APRIL (sAPRIL ${ }^{3(\mathrm{~K}-\mathrm{A})}$ ) with a FLAG-tag at the N-terminus separated by the same linker. The original vector served as a positive control and the correct expression of the plasmids was ascertained by binding to TACl or BCMA.

\section{APRIL precipitation and Western blot}

SAPRIL and SAPRIL ${ }^{3(\mathrm{~K}-\mathrm{A})}(\sim 1 \mu \mathrm{g})$ was incubated in the conditioned medium with $20 \mu$ l heparin-sepharose beads at room temperature for $30 \mathrm{~min}$. Afterwards, beads were washed three times with PBS and incubated with $100 \mathrm{ng}$ recombinant BCMA-Fc in PBS for $1 \mathrm{~h}$ at room temperature. Precipitates were again washed three times and resuspended in Laemmli sample buffer. After boiling for $5 \mathrm{~min}$, samples were separated on a $10 \%$ SDS-PAGE gel and blotted to PVDF. Blots were subsequently blocked in PBS $/ 0.2 \%$ Tween plus $5 \%$ nonfat dry milk and incubated with horseradish peroxidase-coupled anti-FLAG M2 (Sigma) or anti-human-Ig to detect APRIL and BCMA-Fc, respectively. ECL was used according to the manufacturer's instructions to reveal bound antibody.

\section{APRIL-induced proliferation}

A549 cells were treated with MEGA-APRIL with or without $4 \mathrm{IU} / \mathrm{ml}$ heparin for $36 \mathrm{~h}$. During the last $8 \mathrm{~h}$, cells were pulsed with $0.5 \mu \mathrm{Ci}{ }^{3} \mathrm{H}$-thymidine/ well. After this pulse, cells were quickly frozen to lyse all cells and upon defreezing harvested using a standard harvesting protocol. Assays were performed in duplicate or triplicate to minimize variation and percent increase was calculated according to the following method: \%APRILinduced proliferation $=($ CPM with APRIL/CPM without APRIL $) \times 100 \%$. For NIH-3T3 and Jurkat cells, APRIL-induced proliferation was analyzed using the MTS assay according to the manufacturer's instructions (Promega, Leiden, The Netherlands). In short, $10^{4}$ cells were seeded and stimulated with MEGA-APRIL for $36 \mathrm{~h}$. Cells were then incubated with MTS and the cell number was determined using absorbance at $490 \mathrm{~nm}$. Values are given as \%APRIL-induced proliferation $=($ Abs APRILinduced-Abs background/Abs control-Abs background). Assays were performed at least in quadruplate.

\section{B- and T-cell isolation/stimulation}

Mice were housed in the CPV-LUMC, Leiden, The Netherlands and treated according to National and Institutional regulations. Peritoneal cells were isolated with a peritoneal lavage and stained for CD43-PE and IgDFitc (BD biosciences) together with MEGA-APRIL visualization as described above. For $\mathrm{CD}^{+}{ }^{+} \mathrm{T}$-cell costimulation, cells were isolated from the spleen and depleted of B cells using M5-114 mAb plus swine- $\alpha$ rat and goat- $\alpha$-mouse beads. Remaining $T$ cells were stimulated at $5 \times 10^{5}$ cells/well with plate-bound anti-CD3 $(50 \mathrm{ng} / \mathrm{ml})$. Where indicated, increasing amounts of MEGA-APRIL $(0-100 \mathrm{ng} / \mathrm{ml})$ and/or heparin (2 IU/ $\mathrm{ml}$ ) were added together with the $\mathrm{T}$ cells. CD4 ${ }^{+} \mathrm{T}$-cell activation was determined with CD4-APC, CD25-FITC and CD69-PE (BD Biosciences) staining. 


\section{Acknowledgements}

We are indebted to Linde Meyaard, Ingrid Kolfschoten, Martine van Miltenburg, Peter van Veelen and Margreet Kruse for their efforts to clone the putative APRIL receptor. Kees Franken for technical assistance and supplies. We also thank the animal caretakers for keeping the mice clean, and finally, Pascal Schneider for fruitful discussions and Carl Ware for his suggestion to use heparin.

\section{References}

1. Lopez-Fraga M, Fernandez R, Albar JP and Hahne M (2001) Biologically active APRIL is secreted following intracellular processing in the Golgi apparatus by furin convertase. EMBO Rep. 2: 945-951

2. Aggarwal BB (2003) Signalling pathways of the TNF superfamily: a doubleedged sword. Nat. Rev. Immunol. 3: 745-756

3. Mackay F and Ambrose C (2003) The TNF family members BAFF and APRIL: the growing complexity. Cytokine Growth Factor Rev. 14: 311-324

4. Mackay F, Schneider P, Rennert P and Browning J (2003) BAFF AND APRIL: a tutorial on B cell survival. Annu. Rev. Immunol. 21: 231-264

5. Medema JP, Planelles-Carazo L, Hardenberg G and Hahne M (2003) The uncertain glory of APRIL. Cell Death Differ. 10: 1121-1125

6. Stein JV, Lopez-Fraga M, Elustondo FA, Carvalho-Pinto CE, Rodriguez D, Gomez-Caro R, De Jong J, Martinez AC, Medema JP and Hahne M (2002) APRIL modulates B and T cell immunity. J. Clin. Invest. 109: 1587-1598

7. Litinskiy MB, Nardelli B, Hilbert DM, He B, Schaffer A, Casali P and Cerutti A (2002) DCs induce CD40-independent immunoglobulin class switching through BLyS and APRIL. Nat. Immunol. 3: 822-829

8. Castigli E, Scott S, Dedeoglu F, Bryce P, Jabara H, Bhan AK, Mizoguchi E and Geha RS (2004) Impaired IgA class switching in APRIL-deficient mice. Proc. Natl. Acad. Sci. USA 101: 3903-3908

9. Hahne M, Kataoka T, Schroter M, Hofmann K, Irmler M, Bodmer JL, Schneider P, Bornand T, Holler N, French LE, Sordat B, Rimoldi D and Tschopp J (1998) APRIL, a new ligand of the tumor necrosis factor family, stimulates tumor cell growth. J. Exp. Med. 188: 1185-1190

10. Rennert $P$, Schneider $P$, Cachero TG, Thompson J, Trabach L, Hertig S, Holler N, Qian F, Mullen C, Strauch K, Browning JL, Ambrose C and Tschopp J (2000) A soluble form of $B$ cell maturation antigen, a receptor for the tumor necrosis factor family member APRIL, inhibits tumor cell growth. J. Exp. Med. 192 1677-1684

11. Planelles L, Carvalho-Pinto $C E$, Hardenberg G, Smaniotto $S$, Savino W, Gomez-Caro R, Alvarez-Mon M, de Jong J, Eldering E, Martinez AC, Medema JP and Hahne M (2004) APRIL promotes B-1 cell-associated neoplasm. Cancer Cell 6: 399-408

12. Thompson JS, Schneider $P$, Kalled SL, Wang L, Lefevre EA, Cachero TG, MacKay F, Bixler SA, Zafari M, Liu ZY, Woodcock SA, Qian F, Batten M, Madry $C$, Richard Y, Benjamin CD, Browning JL, Tsapis A, Tschopp J and Ambrose C (2000) BAFF binds to the tumor necrosis factor receptor-like molecule B cell maturation antigen and is important for maintaining the peripheral $B$ cell population. J. Exp. Med. 192: 129-135

13. Yu G, Boone T, Delaney J, Hawkins N, Kelley M, Ramakrishnan M, McCabe S, Qiu WR, Kornuc M, Xia XZ, Guo J, Stolina M, Boyle WJ, Sarosi I, Hsu H, Senaldi G and Theill LE (2000) APRIL and TALL-I and receptors BCMA and TACl: system for regulating humoral immunity. Nat. Immunol. 1: 252-256

14. Wu Y, Bressette D, Carrell JA, Kaufman T, Feng P, Taylor K, Gan Y, Cho YH, Garcia AD, Gollatz E, Dimke D, LaFleur D, Migone TS, Nardelli B, Wei P, Ruben SM, Ullrich SJ, Olsen HS, Kanakaraj P, Moore PA and Baker KP (2000) Tumor necrosis factor (TNF) receptor superfamily member TACl is a high affinity receptor for TNF family members APRIL and BLyS. J. Biol. Chem. 275 35478-35485

15. Marsters SA, Yan M, Pitti RM, Haas PE, Dixit VM and Ashkenazi A (2000) Interaction of the TNF homologues BLyS and APRIL with the TNF receptor homologues BCMA and TACl. Curr. Biol. 10: 785-788

16. Wallweber HJ, Compaan DM, Starovasnik MA and Hymowitz SG (2004) The crystal structure of a proliferation-inducing ligand, APRIL. J. Mol. Biol. 343: 283-290
17. Sasisekharan R, Shriver Z, Venkataraman G and Narayanasami U (2002) Roles of heparan-sulphate glycosaminoglycans in cancer. Nat. Rev. Cancer 2: $521-528$

18. Derksen PW, de Gorter DJ, Meijer HP, Bende RJ, van Dijk M, Lokhorst HM, Bloem AC, Spaargaren M and Pals ST (2003) The hepatocyte growth factor/ Met pathway controls proliferation and apoptosis in multiple myeloma. Leukemia 17: 764-774

19. van der Voort R, Taher TE, Wielenga VJ, Spaargaren M, Prevo R, Smit L, David G, Hartmann G, Gherardi E and Pals ST (1999) Heparan sulfatemodified CD44 promotes hepatocyte growth factor/scatter factor-induced signal transduction through the receptor tyrosine kinase c-Met. J. Biol. Chem. 274: 6499-6506

20. Naka D, Ishii T, Shimomura T, Hishida T and Hara H (1993) Heparin modulates the receptor-binding and mitogenic activity of hepatocyte growth factor on hepatocytes. Exp. Cell Res. 209: 317-324

21. David G, Bai XM, Van der Schueren B, Cassiman JJ and Van den Berghe H (1992) Developmental changes in heparan sulfate expression: in situ detection with mAbs. J. Cell Biol. 119: 961-975

22. Cardin $A D$ and Weintraub HJ (1989) Molecular modeling of proteinglycosaminoglycan interactions. Arteriosclerosis 9: 21-32

23. Shulga-Morskaya S, Dobles M, Walsh ME, Ng LG, MacKay F, Rao SP, Kalled SL and Scott ML (2004) B cell-activating factor belonging to the TNF family acts through separate receptors to support B cell survival and T cell-independent antibody formation. J. Immunol. 173: 2331-2341

24. Siegel RM and Lenardo MJ (2001) To B or not to B: TNF family signaling in lymphocytes. Nat. Immunol. 2: 577-578

25. Wrenshall LE, Cerra FB, Carlson A, Bach FH and Platt JL (1991) Regulation of murine splenocyte responses by heparan sulfate. J. Immunol. 147: $455-459$

26. Esko JD and Lindahl U (2001) Molecular diversity of heparan sulfate. J. Clin. Invest. 108: 169-173

27. Gallagher JT (2001) Heparan sulfate: growth control with a restricted sequence menu. J. Clin. Invest. 108: 357-361

28. Tsuda M, Kamimura K, Nakato H, Archer M, Staatz W, Fox B, Humphrey M, Olson S, Futch T, Kaluza V, Siegfried E, Stam L and Selleck SB (1999) The cell-surface proteoglycan Dally regulates Wingless signalling in Drosophila. Nature 400: 276-280

29. Perrimon $N$ and Bernfield $M(2000)$ Specificities of heparan sulphate proteoglycans in developmental processes. Nature 404: 725-728

30. McCormick C, Leduc Y, Martindale D, Mattison K, Esford LE, Dyer AP and Tufaro $F(1998)$ The putative tumour suppressor EXT1 alters the expression of cell-surface heparan sulfate. Nat. Genet. 19: 158-161

31. Alexander CM, Reichsman F, Hinkes MT, Lincecum J, Becker KA, Cumberledge $S$ and Bernfield M (2000) Syndecan-1 is required for Wnt-1induced mammary tumorigenesis in mice. Nat. Genet. 25: 329-332

32. Wielenga VJ, van der Voort R, Taher TE, Smit L, Beuling EA, van Krimpen C, Spaargaren M and Pals ST (2000) Expression of c-Met and heparan-sulfate proteoglycan forms of CD44 in colorectal cancer. Am. J. Pathol. 157: 1563-1573

33. Wielenga VJ, van der Neut R, Offerhaus GJ and Pals ST (2000) CD44 glycoproteins in colorectal cancer: expression, function, and prognostic value. Adv. Cancer Res. 77: 169-187

34. Derksen PW, Keehnen RM, Evers LM, van Oers MH, Spaargaren M and Pals ST (2002) Cell surface proteoglycan syndecan-1 mediates hepatocyte growth factor binding and promotes Met signaling in multiple myeloma. Blood 99: 1405-1410

35. Delehedde M, Seve M, Sergeant N, Wartelle I, Lyon M, Rudland PS and Fernig DG (2000) Fibroblast growth factor-2 stimulation of p42/44MAPK phosphorylation and IkappaB degradation is regulated by heparan sulfate/heparin in rat mammary fibroblasts. J. Biol. Chem. 275: 33905-33910

36. Cadigan KM (2002) Regulating morphogen gradients in the Drosophila wing. Semin. Cell Dev. Biol. 13: 83-90

37. Giraldez AJ, Copley RR and Cohen SM (2002) HSPG modification by the secreted enzyme Notum shapes the Wingless morphogen gradient. Dev. Cell 2: $667-676$

38. Kirkpatrick CA, Dimitroff BD, Rawson JM and Selleck SB (2004) Spatial regulation of Wingless morphogen distribution and signaling by Dally-like protein. Dev. Cell 7: 513-523 
HSPG bind APRIL $\mathrm{J}$ Hendriks et al
43. Huard B, Schneider P, Mauri D, Tschopp J and French LE (2001) T cell costimulation by the TNF ligand BAFF. J. Immunol. 167: 6225-6231

44. von Bulow GU and Bram RJ (1997) NF-AT activation induced by a CAML-interacting member of the tumor necrosis factor receptor superfamily. Science 278: 138-141

45. Ng LG, Sutherland AP, Newton R, Qian F, Cachero TG, Scott ML, Thompson JS, Wheway J, Chtanova T, Groom J, Sutton IJ, Xin C, Tangye SG, Kalled SL, Mackay F and Mackay CR (2004) B cell-activating factor belonging to the TNF family (BAFF)- $R$ is the principal BAFF receptor facilitating BAFF costimulation of circulating T and B cells. J. Immunol. 173: 807-817

46. Zacharski LR, Ornstein DL and Mamourian AC (2000) Low-molecular-weight heparin and cancer. Semin. Thromb. Hemost. 26 (Suppl 1): 69-77 